\title{
Complex and Inverse Complex Dynamics of Fractals using Ishikawa Iteration
}

\author{
Ashish Negi \\ Associate Professor \\ Dept. of Computer science and \\ Engineering \\ G.B.Pant Engineering College \\ Ghurdauri, Pauri
}

\author{
Shashank Lingwal \\ Dept. of Computer Science and \\ Engineering \\ G.B.Pant Engineering College \\ Ghurdauri, Pauri
}

\author{
Yashwant Singh Chauhan \\ Astt. Professor \\ Dept. of Computer Science and \\ Engineering \\ G.B.Pant Engineering College \\ Ghurdauri, Pauri
}

\begin{abstract}
Complex graphics of dynamical system have been a subject of intense research nowadays. The fractal geometry is the base of these beautiful graphical images. Many researchers and authors have worked to study the complex nature of the two most popular sets in fractal geometry, the Julia set and the Mandelbrot set, and proposed their work in various forms using existing tools and techniques. Still researches are being conducted to study and reveal the new concepts unexplored in the complexities of these two most popular sets of fractal geometry. Recently, Ashish Negi, Rajeshri Rana and Yashwant S. Chauhan are among those researchers who have contributed a lot in the area of Fractal Geometry applications. In this paper we review the recently done work on complex and inverse complex functions for producing beautiful fractal graphics. The reviewed work mainly emphasizes on the study of the nature of complex and inverse complex functional dynamics using Ishikawa iterates and existence of relative superior Mandel-bar set.
\end{abstract}

\section{Keywords}

Fractals, Complex dynamics, Inverse Complex dynamics, Relative Superior Mandelbrot Set, Relative Superior Julia Set, Ishikawa Iteration, Relative Superior Mandel-bar Set.

\section{INTRODUCTION}

In 1918, French mathematician Gaston Julia [9] investigated the iteration process of complex function and attained a Julia set, which is a landmark in the field of fractal theory. The object Mandelbrot set on the other hand was given by Benoit B. Mandelbrot [11] in 1979. The visual complexity, beauty and self similarity of these structures have made these subjects of a wide area of intense research right from its advent. The various extensions and variants of both of these sets have been extensively studied using Picard's iterations. We have applied in this research article a new iteration process called Ishikawa iteration.

The fractals generated from the self-squared function $z \rightarrow z^{2}+c$, where $z$ and $c$ are complex quantities, have been studied extensively in literature [5, 6, $7 \& 14]$. Recently, the generalized transformation function $z \rightarrow z^{-n}+c$ for positive integer value of $n$ has been considered by K.W.Shirriff [14]. The $z$ plane fractal images for the function $z_{n+1} \leftarrow z_{n}^{\alpha}+c$ for positive and negative, both integer and non-integer values of $n$ have been presented by Gujar et al. along with some conjectures about their visual characteristics [6,7].

Several programs and papers have used escape-time methods to produce images of fractals based on the complex mapping $z \rightarrow\left(z^{n}+c\right)^{-1}$, where exponent $\mathrm{n}$ is a positive integer. On the other hand, Shizuo [15], has presented the various properties of Multicorns and Tricorns for simple complex function, where $\mathrm{z}$ and $\mathrm{c}$ are complex quantities. Shizuo[16]has also quoted the Multicorns as the generalized Tricorn or Tricorn of higher order. The dynamics of anti-polynomial $z \rightarrow \bar{z}^{d}+c$ of complex polynomial $z^{d}+c$, where $d \geq 2$, leads to interesting Tricorns and Multicorns antifractals with respect to function iteration[4, 15, 16]. Multicorns are symmetrical objects. Their symmetry has been studied by Lau and Schieicher [10]. The study of connectedness locus for anti-holomorphic polynomials $\vec{z}^{2}+c$ defined as Tricorns coined by Milnor, plays an intermediate role between quadratic and cubic polynomials. Crowe etal.[3] considered as in formal analogy with Mandelbrot set and named it as Mandel-bar set and also brought its features bifurcations along axis rather than at points. Milnor [12] found it as a real slice of cubic connected locus. Winters [17] showed it as boundary along the smooth arc.

In this paper we considered the transformation (for studying complex dynamics) of the functions $z \rightarrow z^{2}+c, n \geq 2$ and $z \rightarrow z^{-n}+c, n \geq 2$, and transformation (for studying inverse complex dynamics) of the function $z \rightarrow\left(z^{n}+c\right)^{-1}$, for $n \geq 2$, and analysed the $z$ plane fractal images for the first function and $c$ plane fractal images for the second function, generated from Ishikawa iterations of these functions using Ishikawa iteration procedure. We explored the drastic changes that occur in visual characteristics of the images for different integer and noninteger values of $n$.

\section{ELABORATION OF CONCEPTS INVOLVED}

\subsection{Mandelbrot Set}

Definition 1. The Mandelbrot set $M$ for the quadratic $Q_{C}(z)=\mathrm{z}^{2}+\mathrm{c}$ is defined as the collection of all 
$c \in C$ for which the orbit of point 0 is bounded, that is, $M=\left\{c \in C:\left\{Q_{c}^{n}(\mathrm{O})\right\} ; n=0,1,2,3 \ldots\right.$ is bounded $\}$ An equivalent formulation is

$M=\left\{c \in C:\left\{Q_{c}^{n}(0)\right.\right.$ does not tends to $\infty$ as $\left.\left.n \rightarrow \infty\right\}\right\}$ We choose the initial point 0 , as 0 is the only critical point of $\mathrm{Q}_{\mathrm{c}}$.

\subsection{Julia Set}

Definition 2. The set of points $K$ whose orbits are bounded under the iteration function of $\mathrm{Q}_{\mathrm{c}}(\mathrm{z})$ is called the Julia set. We choose the initial point 0 , as 0 is the only critical point of $\mathrm{Q}_{\mathrm{c}}(\mathrm{z})$.

\subsection{Ishikawa Iteration}

Definition 3. Ishikawa Iterates [8]: Let $X$ be a subset of real or complex number and $f: X \rightarrow X$ for all $x_{0} \in X$, we have the sequence $\left\{x_{n}\right\}$ and $\left\{y_{n}\right\}$ in $X$ in the following manner:

$y_{n}=S_{n}^{\prime} f\left(x_{n}\right)+\left(1-S^{\prime}{ }_{n}\right) x_{n}$

$x_{n+1}=S_{n} f\left(y_{n}\right)+\left(1-S_{n}\right) x_{n}$

where $\mathrm{O} \leq S^{\prime}{ }_{n} \leq 1, \quad \mathrm{O} \leq S_{n} \leq 1$ and $S^{\prime}{ }_{n} \& S_{n}$ are both convergent to non-zero number.

\subsection{Relative Superior Orbit}

Definition 4. [13] The sequence $x_{n}$ and $y_{n}$ constructed above is called Ishikawa sequence of iteration or relative superior sequence of iterates. We denote it by $\operatorname{RSO}\left(x_{0}, s_{n}, s_{n}{ }_{n}, t\right)$.

Notice that $\operatorname{RSO}\left(x_{0}, s_{n}, s_{n}{ }_{n}, t\right)$ with $s_{n}{ }_{n}=1$ is $S O\left(x_{0}, s_{n}, t\right)$ i.e. mann's orbit and if we place $s_{n}=s_{n}{ }_{n}=1$ then $\operatorname{RSO}\left(x_{0}, s_{n}, s^{\prime}{ }_{n}, t\right)$ reduce to $\boldsymbol{O}\left(x_{0}, t\right)$. We remark that Ishikawa orbit $\operatorname{RSO}\left(x_{0}, s_{n}, s_{n}^{\prime}, t\right)$ with $s_{n}^{\prime}=1 / 2$ is relative superior orbit.

\subsection{Relative Superior Mandelbrot Set}

Now we define Mandelbrot set for the function with respect to Ishikawa iterates. We call them as Relative Superior Mandelbrot sets.

Definition 5. [13] Relative Superior Mandelbrot set RSM for the function of the form $Q_{c}(z)=z^{n}+c$, where $\mathrm{n}=$ $1,2,3, \ldots$ is defined as the collection of $c \in C$ for which the orbit of 0 is bounded i.e. $R S M=\left\{c \in C: Q_{c}^{k}(0): k=0,1,2,3 \ldots\right\}$ is bounded.

In functional dynamics, we have existence of two different types of points. Points that leave the interval after a finite number are in stable set of infinity. Points that never leave the interval after any number of iterations have bounded orbits. So, an orbit is bounded if there exists a positive real number.

\subsection{Relative Superior Julia Set}

Definition 6. [2] The set of points RSK whose orbits are bounded under relative superior iteration of function $Q(z)$ is called Relative Superior Julia sets. Relative Superior Julia set of Q is boundary of Julia set RSK.

\subsection{Mandel-bar Set}

Definition 7. [2] The Mandel-bar set $A_{c}$, for the quadratic $A_{c}(z)=z^{\prime n}+c$ is defined as the collection of all $c \in C$ for which the orbit of point 0 is bounded, that is, $A_{c}=\left\{c \in C: A_{c}(\mathrm{O})_{n=0,1,2,3, \ldots}\right.$ is bounded $\}$.

$$
\begin{aligned}
& \text { An } \\
& A_{c}=\left\{c \in C: A_{c}(0) \text { not tends to } \infty \text { as } \mathrm{n} \rightarrow \infty\right\}
\end{aligned}
$$

\subsection{Relative Superior Mandel-bar Set}

Definition 8. [13] Relative superior Mandel-bar set RSMB for the function of the form $Q_{c}(z)=z^{n}+c$, where $\mathrm{n}=1,2,3,4, \ldots$ is defined as the collection of $c \in C$ for which the orbit of 0 is bounded i.e. $R S M B=\left\{c \in C: Q_{c}{ }^{k}(0): k=0,1,2,3, \ldots\right\}$ is bounded.

\section{GENERATING PROCESS}

The basic principle of generating fractals employs the iterative formula: $z_{n+1} \leftarrow f\left(z_{n}\right)$ where $\mathrm{z}_{0}=$ the initial valueof $\mathrm{z}$, and $z_{i}=$ the value of complex quantity $z$ at the $i^{\text {th }}$ iteration $[6$, 7]. For example, the Mandelbrot's self-squared function for generating fractal is: $f(z)=z^{2}+c$, where $z$ and $c$ are both complex quantities. We propose the use of transformation function $z \rightarrow z^{n}+c, n \geq 2$ and $z \rightarrow\left(z^{n}+c\right)^{-1}$ for generating fractal images with respect to Ishikawa iterates, where $\mathrm{z}$ and $\mathrm{c}$ are the complex quantities and $\mathrm{n}$ is a real number. Each of these fractal images is constructed as twodimensional array of pixel. Each pixel is represented by a pair of $(\mathrm{x}, \mathrm{y})$ coordinates. The complex quantities $\mathrm{z}$ and $\mathrm{c}$ can be represented as:

$$
\begin{aligned}
& z=z_{x}+i z_{y} \\
& c=c_{x}+i c_{y}
\end{aligned}
$$

where $i=\sqrt{(-1)}$ and $\mathrm{z}_{\mathrm{x}}, \mathrm{c}_{\mathrm{x}}$ are the real parts and $\mathrm{z}_{\mathrm{y}}, \mathrm{c}_{\mathrm{y}}$ are the imaginary parts of $\mathrm{z}$ and $\mathrm{c}$ respectively. The pixel coordinates $(\mathrm{x}, \mathrm{y})$ may be associated with $\left(\mathrm{c}_{\mathrm{x}}, \mathrm{c}_{\mathrm{y}}\right)$ or $\left(\mathrm{z}_{\mathrm{x}}, \mathrm{z}_{\mathrm{y}}\right)$.

Based on this concept, the fractal images can be classified as follows:

(a) z-Plane fractals, wherein $(\mathrm{x}, \mathrm{y})$ is a function of $\left(z_{x}, z_{y}\right)$

(b) c-Plane fractals, wherein $(\mathrm{x}, \mathrm{y})$ is a function of $\left(c_{x}, c_{y}\right)$.

In the literature, the fractals for $\mathrm{n}=2$ in $\mathrm{z}$ plane are termed as the Mandelbrot set while the fractals for $n=2$ in $c$ plane are known as Julia sets [14] 


\section{ESCAPE CRITERION FOR RELATIVE SUPERIOR JULIA AND MANDELBROT SETS}

\subsection{Escape Criterion for Quadratics}

[13] Suppose that $|z|>\max \left\{|c|, 2 / s, 2 / s^{\prime}\right\}$, then $\left|z_{n}\right|>(1+\lambda)^{n}|z|$ and $|z| \rightarrow \infty$ as $n \rightarrow \infty$. So, $|z| \geq|c|$ and $|z|>2 / s$ as well as $|z|>2 / s^{\prime}$ shows the escape criteria for quadratics.

\subsection{Escape Criterion for Cubics}

[13] Suppose $|z|>\max \left\{|b|,(|a|+2 / s)^{1 / 2},\left(|a|+2 / s^{\prime}\right)^{1 / 2}\right\}$ then $\left|z_{n}\right| \rightarrow \infty$ as $n \rightarrow \infty$. This gives the escape criterion for cubic polynomials.

\subsection{General Escape Criterion}

[13] Consider $|z|>\max \left\{|c|,(2 / s)^{1 / 2},\left(2 / s^{\prime}\right)^{1 / 2}\right\}$ then $\left|z_{n}\right| \rightarrow \infty$ as $n \rightarrow \infty$ is the escape criterion.

Note that the initial value $\mathrm{z}_{0}$ should be infinity, since infinity is the critical point of $z \rightarrow\left(z^{n}+c\right)^{-1}$. However, instead of starting with $\mathrm{z}_{0}=$ infinity, it is simpler to start with $\mathrm{z}_{1}=\mathrm{c}$, which yields the same result. A critical point of $z \rightarrow F(z)+c$ is a point where $F^{\prime}(z)=0$.

\section{SIMULATIONS AND RESULTS}

Generation of Relative Superior Mandelbrot set

Fig.1: For cubic function [1]: $\mathrm{s}^{\prime}=0.8, \mathrm{~s}^{\prime}=0.3, \mathrm{n}=3.2$

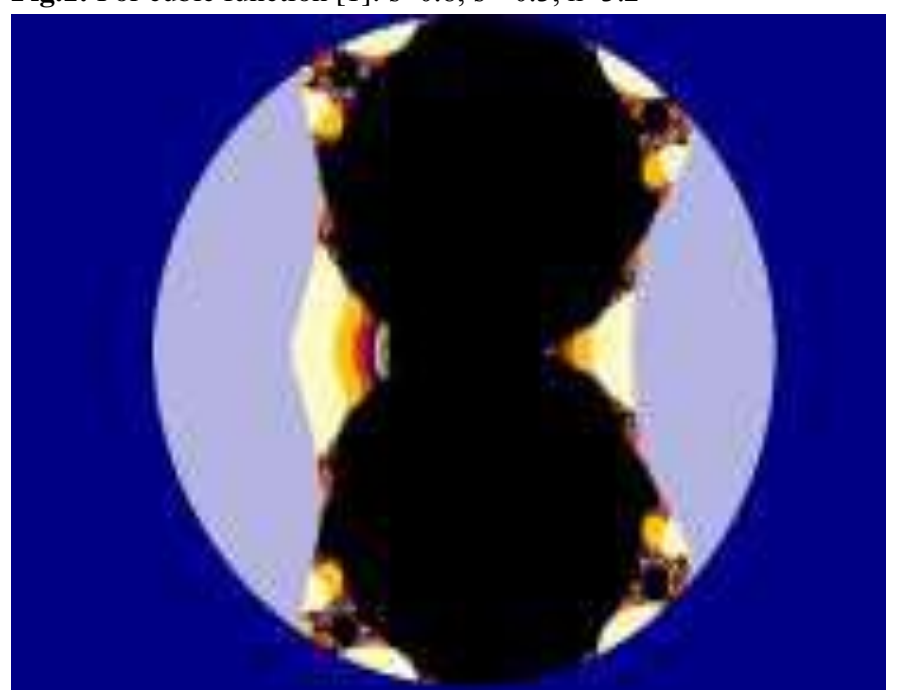

Fig.2: For cubic function: $\mathrm{s}^{=}=0.8, \mathrm{~s}^{\prime}=0.3, \mathrm{n}=3.8$

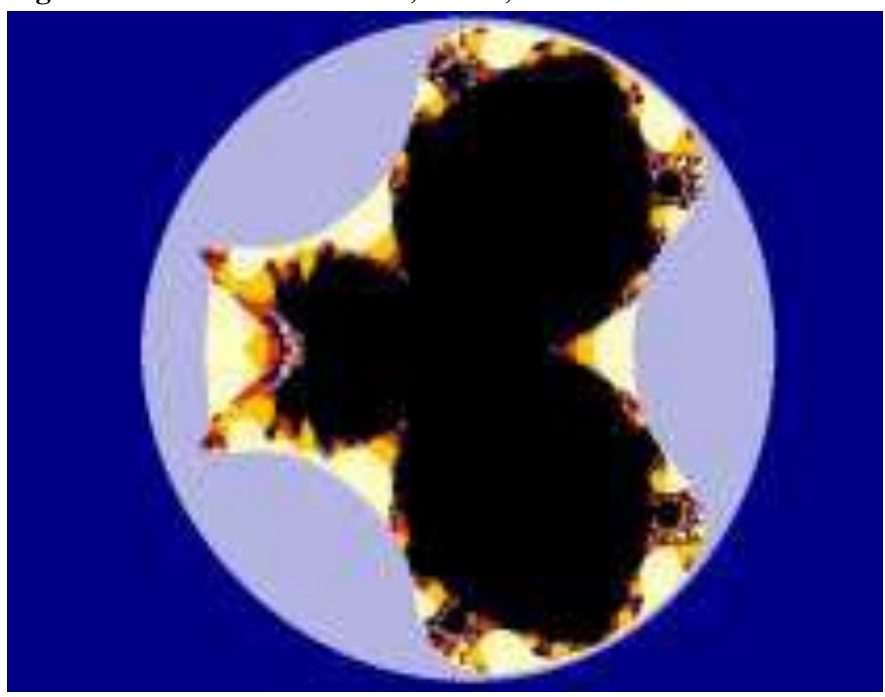

Fig.3: For bi-quadratic function: $\mathrm{s}^{\prime}=0.5, \mathrm{~s}^{\prime}=0.4, \mathrm{n}=4.2$

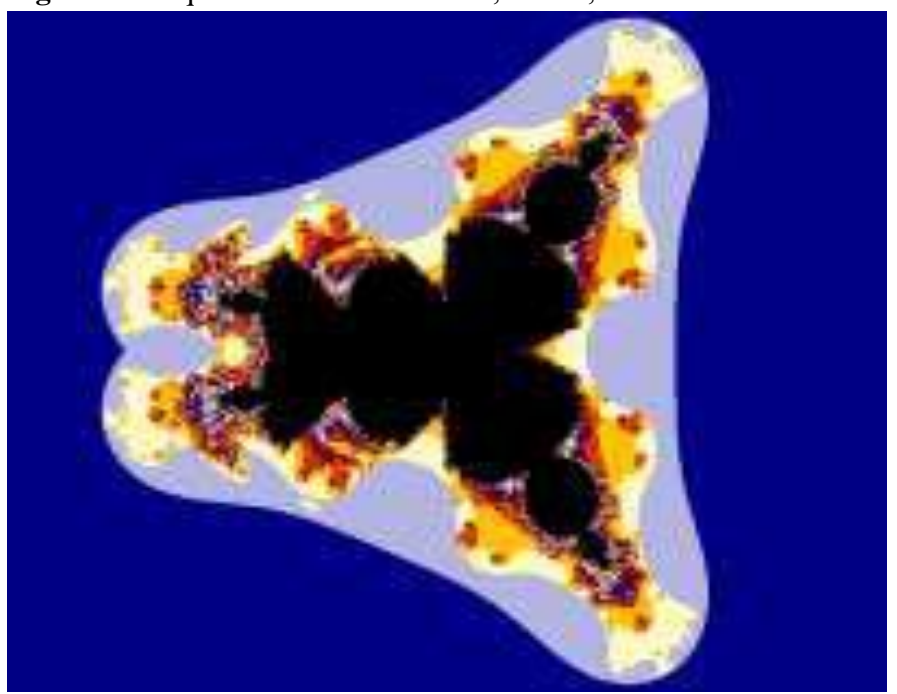

Fig.4: For bi-quadratic function: $s^{\prime}=0.5, s^{\prime}=0.4, n=4.8$

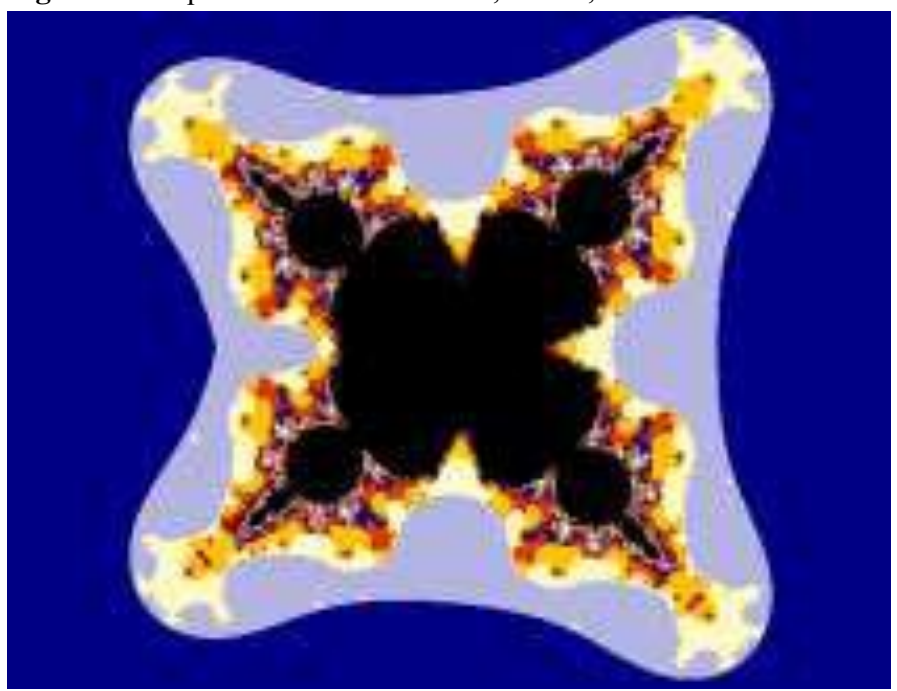

Generalization of Relative Superior Mandelbrot Set 
Fig.5: $\mathrm{s}=0.4, \mathrm{~s}^{\prime}=0.3, \mathrm{n}=15.8$

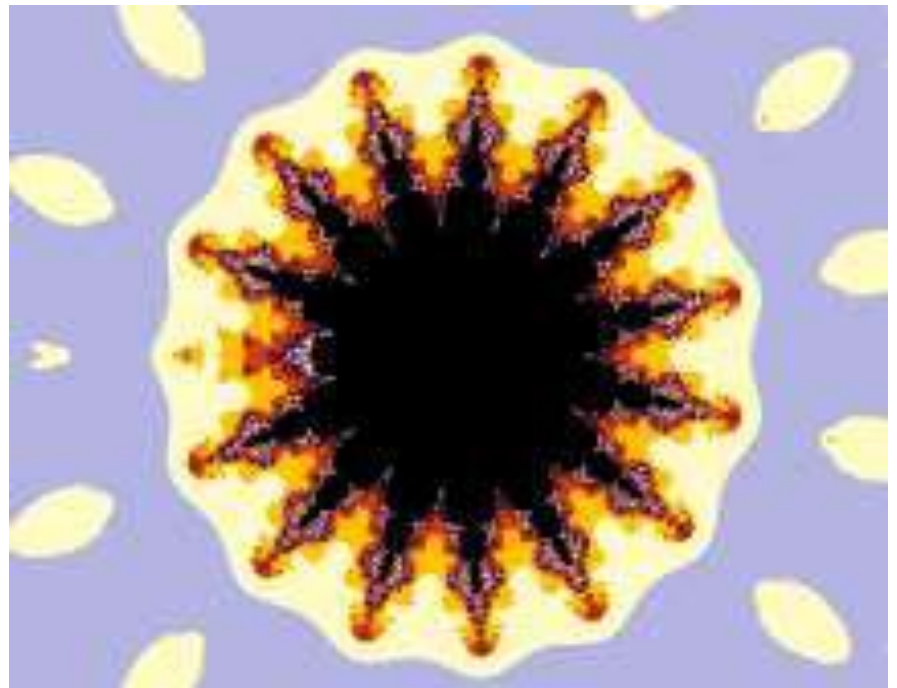

Fig.6: $\mathrm{s}=0.5, \mathrm{~s}^{\prime}=0.4, \mathrm{n}=16.8$

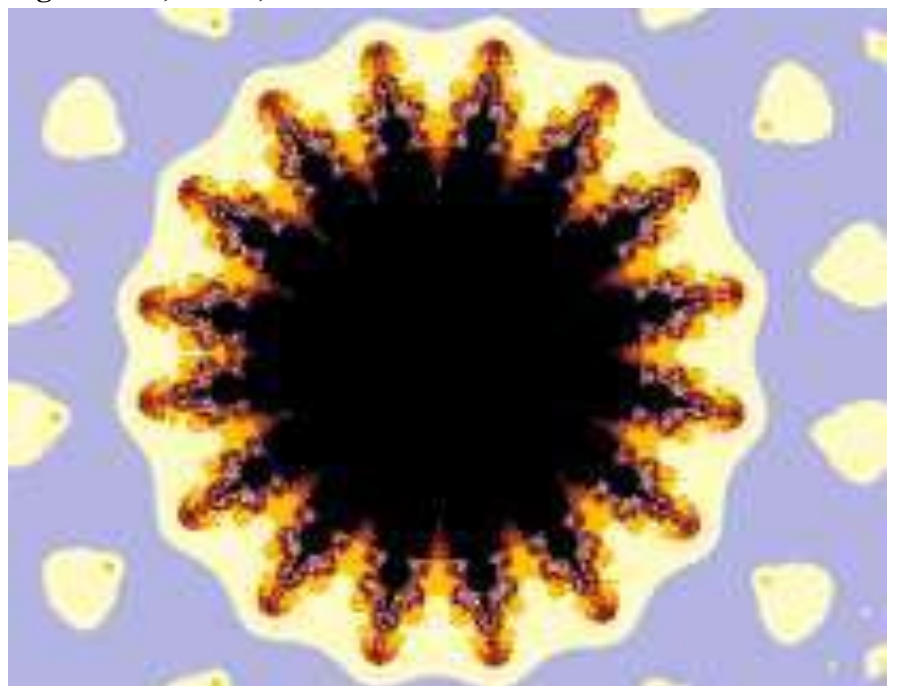

\section{Generation of Relative Superior Julia Sets:}

(for cubic function)

Fig.7: $\mathrm{s}=0.5, \mathrm{~s}=0.4, \mathrm{n}=3.2$

c $=0.03488180321-0.01680604855 \mathrm{i}$

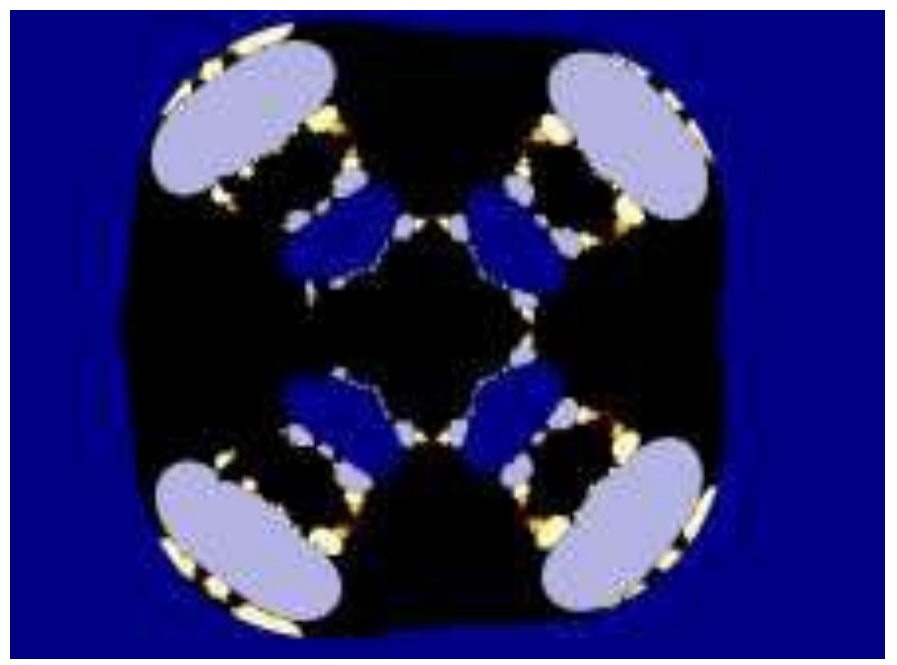

Fig.8: $\mathrm{s}=0.5, \mathrm{~s}=0.4, \mathrm{n}=3.8$

$\mathrm{c}=-0.0442117701+0.03592300032 \mathrm{i}$

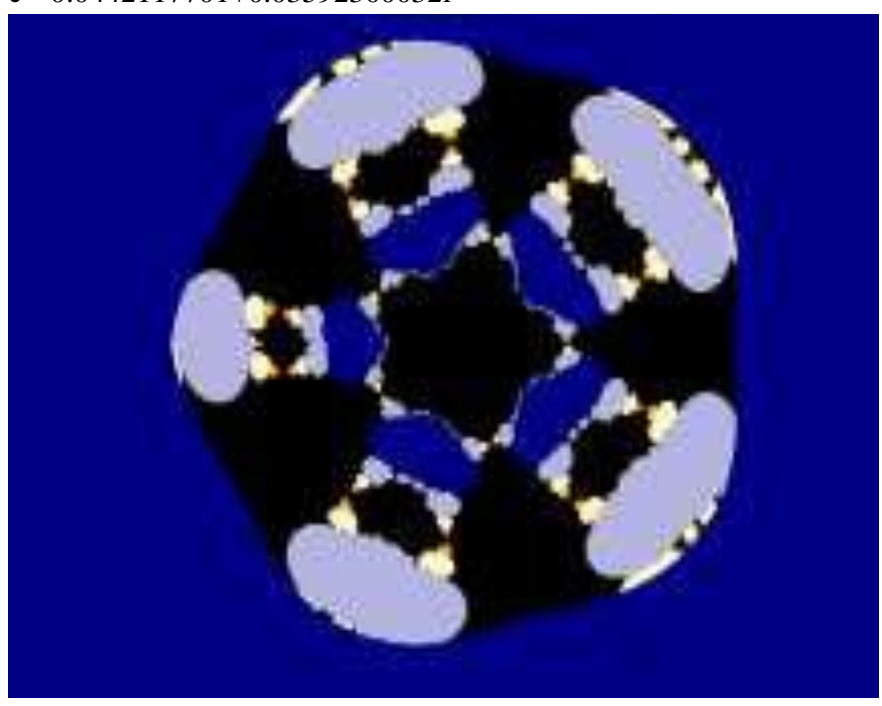

(for bi-quadratic function)

Fig.9: $\mathrm{s}=0.8, \mathrm{~s}^{\prime}=0.2, \mathrm{n}=4.2$

$\mathrm{c}=0.04015470789+0.03592299963 \mathrm{i}$

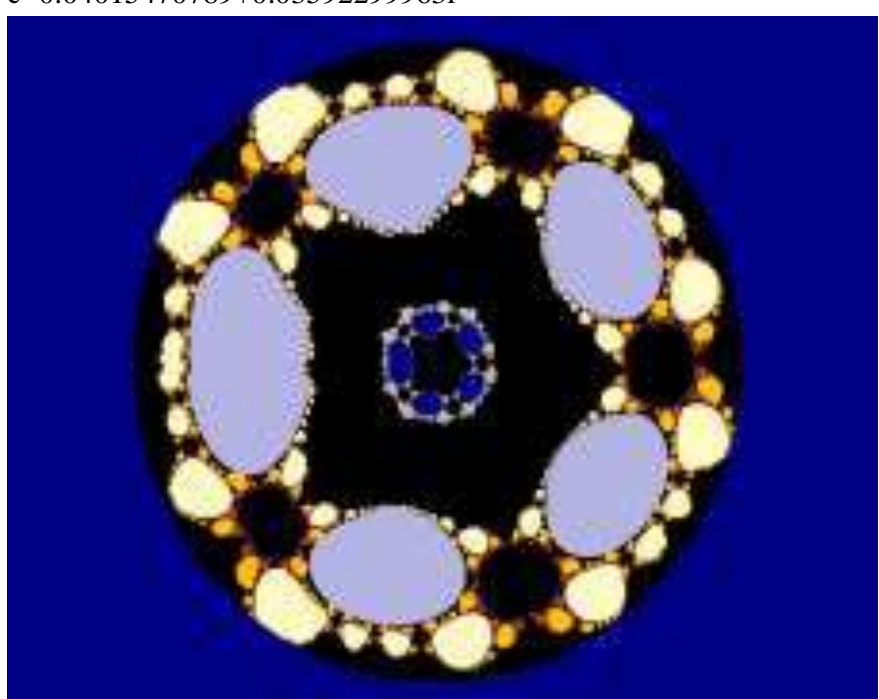

Fig.10: $\mathrm{s}=0.8, \mathrm{~s}=0.2, \mathrm{n}=4.8$

$\mathrm{c}=-0.01784724577+0.03065009474 \mathrm{i}$

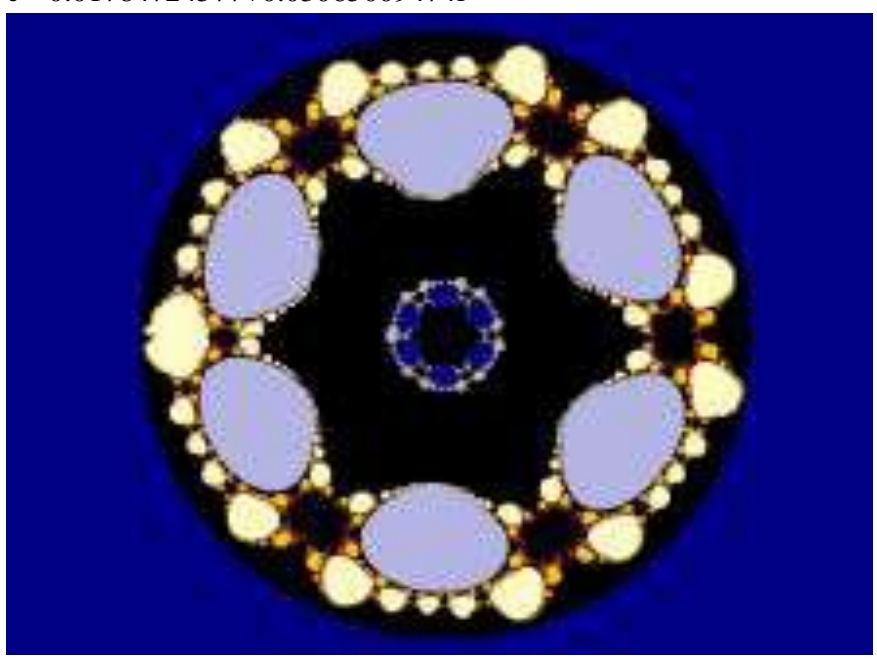


Generalization of Relative Superior Julia Sets:

Fig.11: $\mathrm{s}=0.5, \mathrm{~s}^{\prime}=0.4, \mathrm{n}=15.8$

$\mathrm{c}=-0.001391094496+0.005718433219 \mathrm{i}$

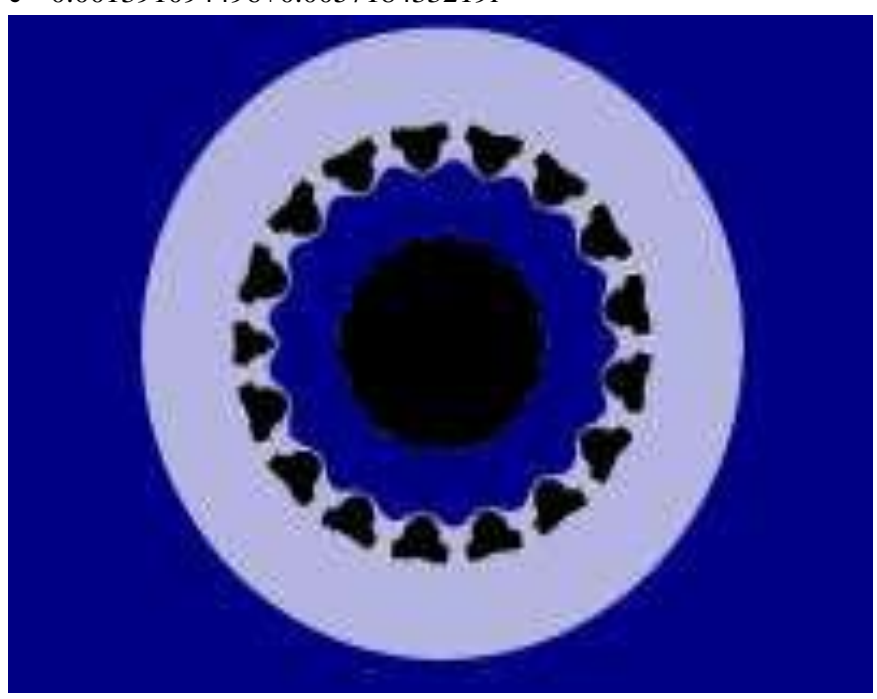

Fig.12: $\mathrm{s}=0.5, \mathrm{~s}^{\prime}=0.4, \mathrm{n}=16.8$

$\mathrm{c}=-0.06389131715+0.02134348888 \mathrm{i}$

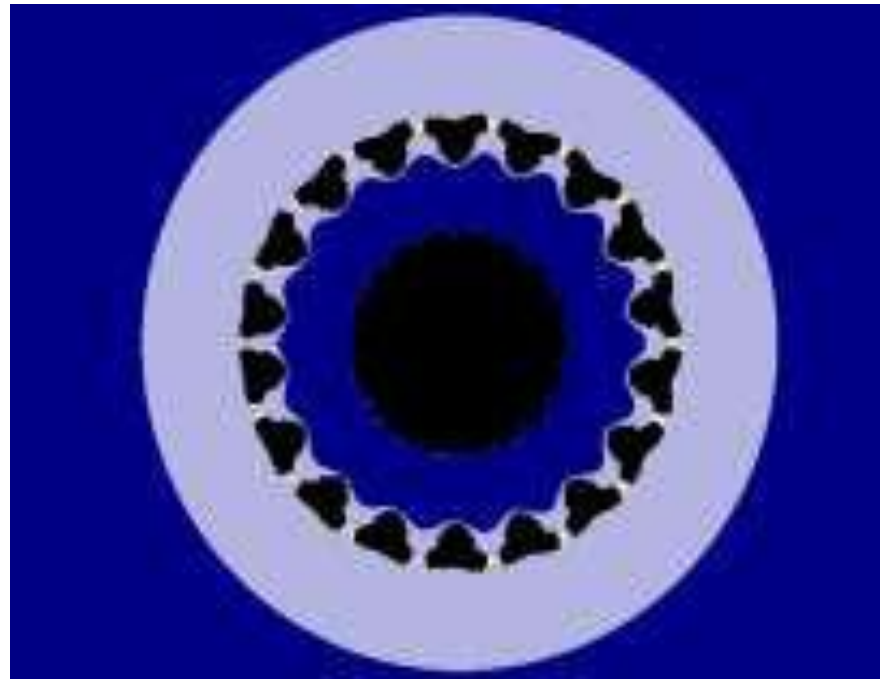

Fixed points :

Fixed points of Quadratic Polynomial [13] :

Table 1: Orbit of $\mathrm{F}(\mathrm{z})$ at $\mathrm{s}=0.5$ and $\mathrm{s}=0.1$

for $(\mathrm{z} 0=-0.01192288639+0.01042379668 \mathrm{i})$

\begin{tabular}{|c|c|c|c|}
\hline $\begin{array}{c}\text { Number of } \\
\text { iteration } \mathbf{i}\end{array}$ & $|\mathbf{F}(\mathbf{z})|$ & $\begin{array}{c}\text { Number of } \\
\text { iteration } \mathbf{i}\end{array}$ & $|\mathbf{F}(\mathbf{z})|$ \\
\hline 1 & 0.015837 & 6 & 0.85943 \\
\hline 2 & 0.98458 & 7 & 0.85943 \\
\hline 3 & 0.86429 & 8 & 0.85942 \\
\hline 4 & 0.85883 & 9 & 0.85942 \\
\hline 5 & 0.85933 & 10 & 0.85942 \\
\hline
\end{tabular}

Fig.13: Observation : the value converges to a fixed point after 08 iterations

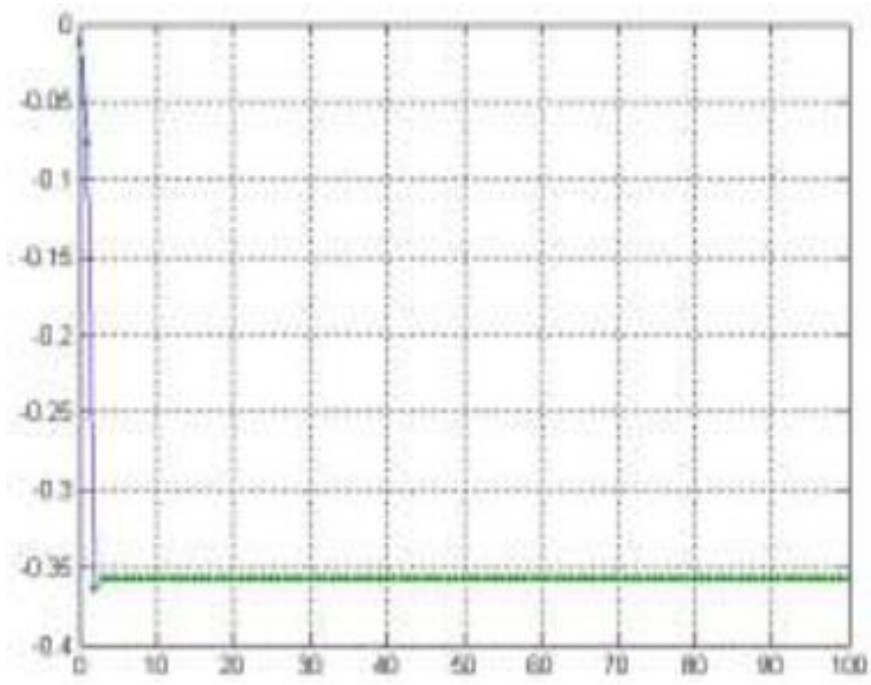

Fixed points of Cubic polynomial [13]

Table 2 : Orbit of $\mathrm{F}(\mathrm{z})$ at $\mathrm{s}=0.5$ and $\mathrm{s}^{\prime}=0.1$

for $(\mathrm{z} 0=-0.00888346751+0.01650347336 \mathrm{i})$

\begin{tabular}{|c|c|c|c|}
\hline $\begin{array}{c}\text { Number of } \\
\text { iteration } \mathbf{i}\end{array}$ & $|\mathbf{F}(\mathbf{z})|$ & $\begin{array}{c}\text { Number of } \\
\text { iteration } \mathbf{i}\end{array}$ & $|\mathbf{F}(\mathbf{z})|$ \\
\hline 1 & 0.018742 & 6 & 0.86749 \\
\hline 2 & 0.97928 & 7 & 0.86747 \\
\hline 3 & 0.85738 & 8 & 0.86747 \\
\hline 4 & 0.86871 & 9 & 0.86747 \\
\hline 5 & 0.86732 & 10 & 0.86747 \\
\hline
\end{tabular}

Fig.14: Observation : the value converges to a fixed point after 07 iterations

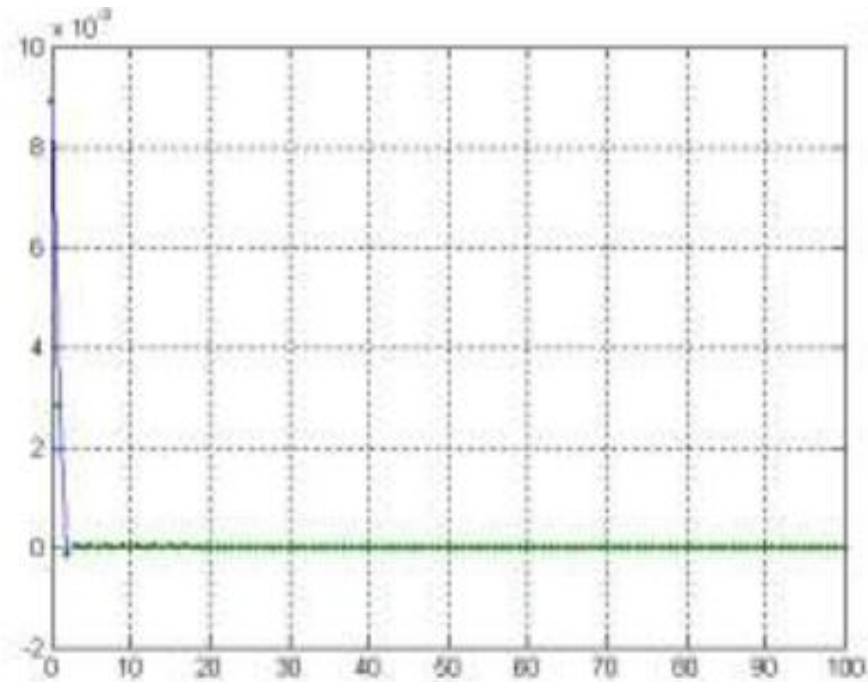


Fixed points of Bi-quadratic polynomial [13]

Table 3 : Orbit of $\mathrm{F}(\mathrm{z})$ at $\mathrm{s}=0.5$ and $\mathrm{s}^{\prime}=0.1$

for $(\mathrm{z} 0=-0.01573769494+0.03678871897 \mathrm{i})$

\begin{tabular}{|c|c|c|c|}
\hline $\begin{array}{c}\text { Number of } \\
\text { iteration i }\end{array}$ & $|\mathbf{F}(\mathbf{z})|$ & $\begin{array}{c}\text { Number of } \\
\text { iteration } \mathbf{i}\end{array}$ & $|\mathbf{F}(\mathbf{z})|$ \\
\hline 1 & 0.040014 & 8 & 0.8968 \\
\hline 2 & 0.98215 & 9 & 0.89704 \\
\hline 3 & 0.90556 & 10 & 0.89699 \\
\hline 4 & 0.88426 & 11 & 0.89699 \\
\hline 5 & 0.90308 & 12 & 0.89699 \\
\hline 6 & 0.89476 & 13 & 0.89699 \\
\hline 7 & 0.8977 & 14 & 0.89699 \\
\hline
\end{tabular}

Fig.15: Observation : the value converges to a fixed point after 10 iterations

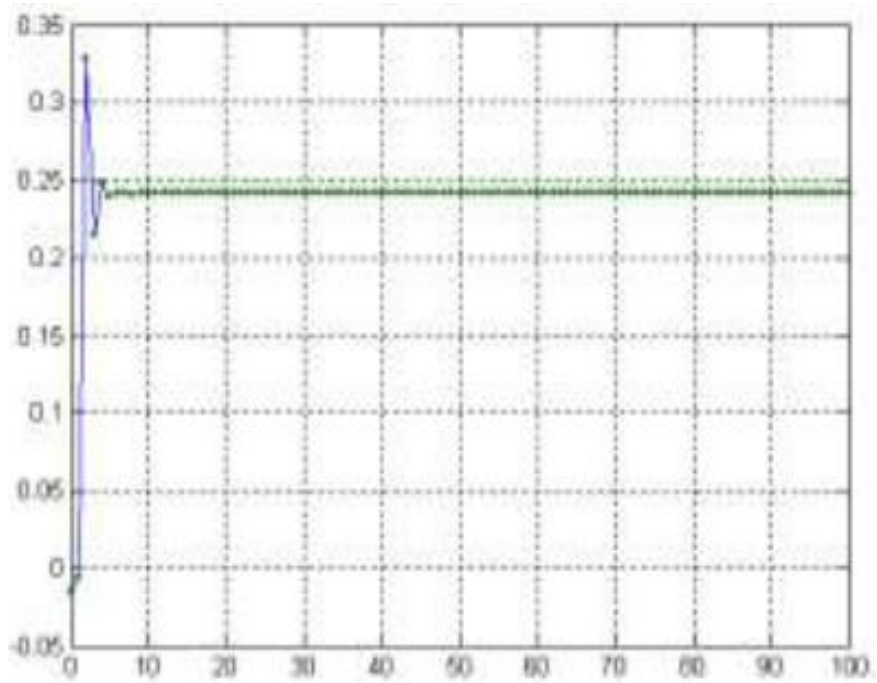

Generation of Relative Superior Mandelbrot Set:

Fig.16: For quadratic function: $\mathrm{s}=0.8, \mathrm{~s}^{\prime}=0.3$

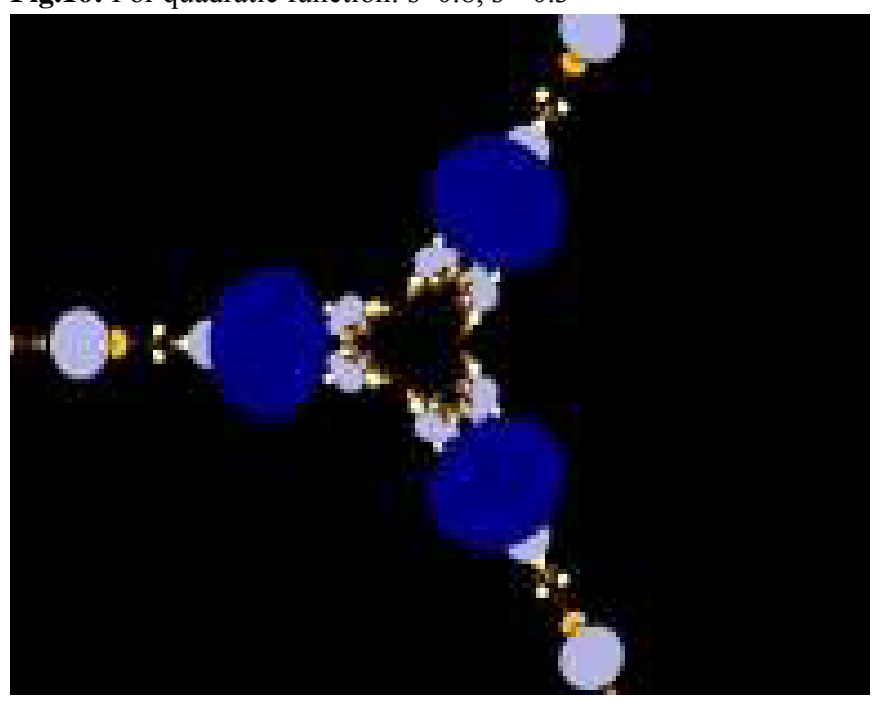

Fig.17: For cubic function: $s=0.8, s^{\prime}=0.3$

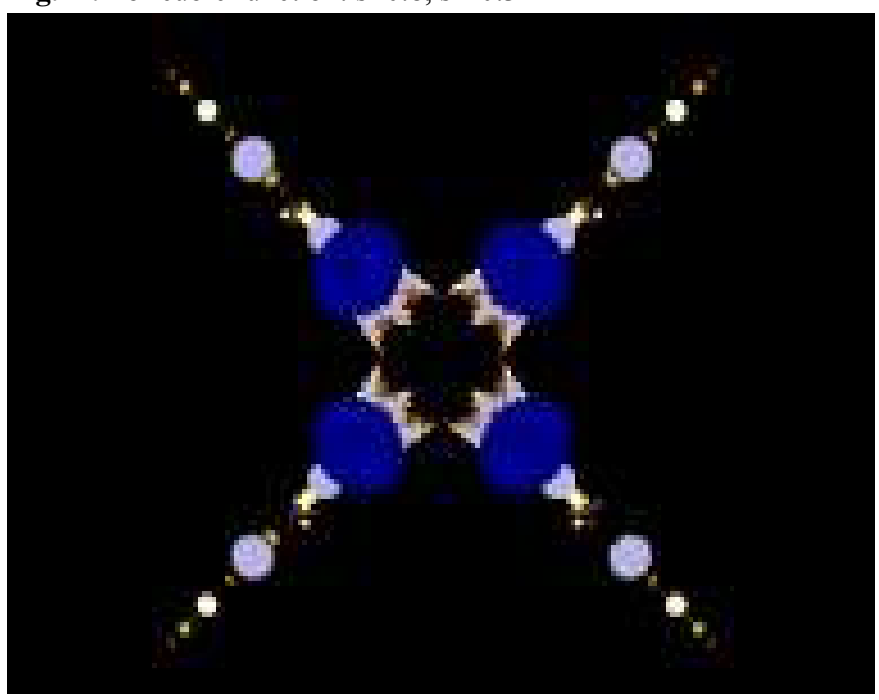

Generation of Relative Superior Julia Sets:

Fig.18: For quadratic function: $\mathrm{s}=0.5, \mathrm{~s}=0.4$ $\mathrm{c}=0.002169194079+0.465750756 \mathrm{i}$

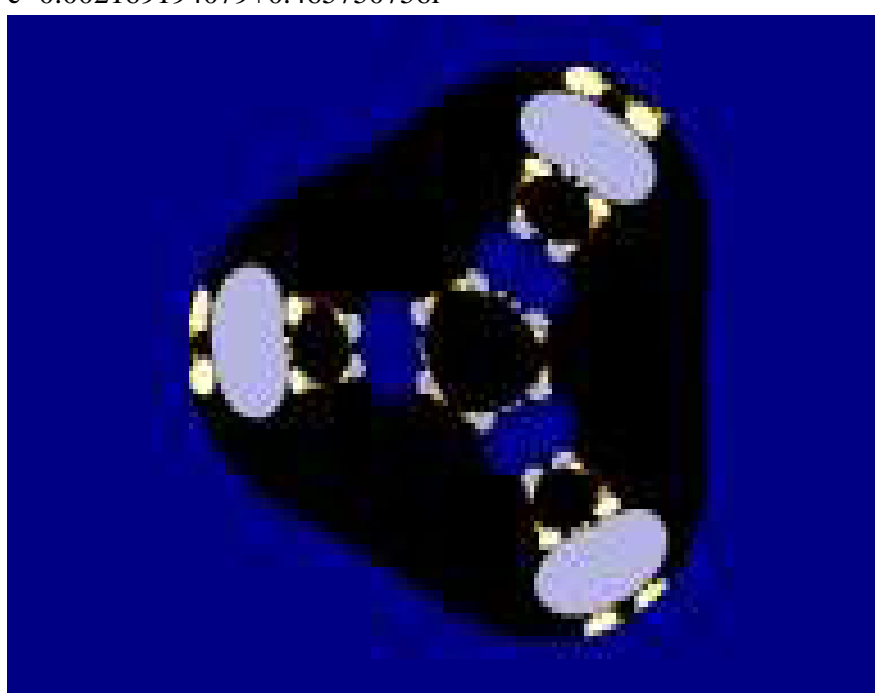

Fig.19: For bi-quadratic function: $\mathrm{s}=0.8, \mathrm{~s}^{\prime}=0.3$, $\mathrm{c}=-0.0227144337+0.04376545773 \mathrm{i}$

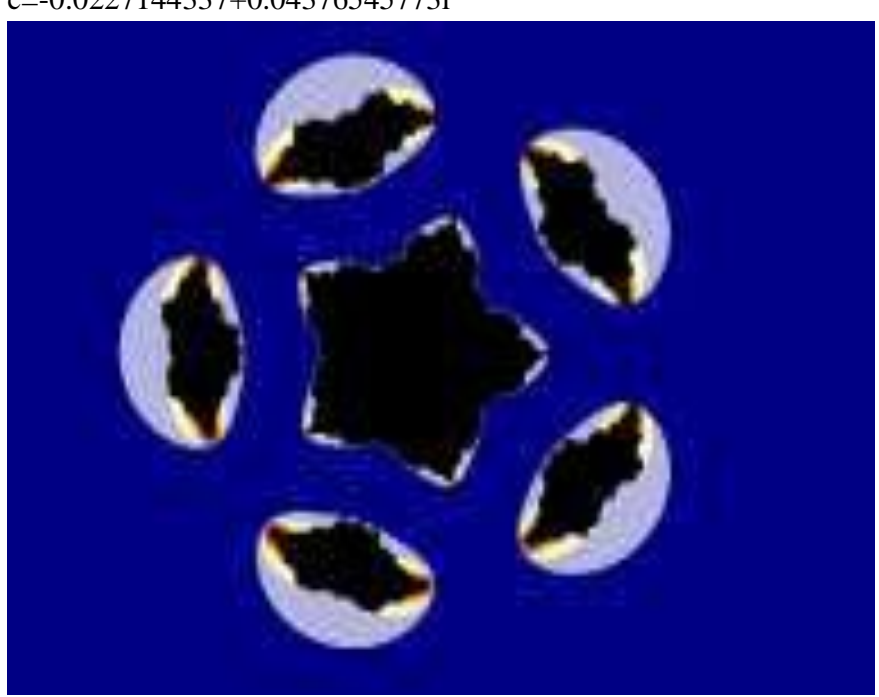




\section{Fixed points :}

Fixed points for quadratic polynomial [2]:

Table 4 : Orbit of $F(z)$ at $s=0.5$ and s' $=0.7$

for $(z 0=-0.6160374839+0.0135629073 i)$

\begin{tabular}{|c|c|c|c|}
\hline $\begin{array}{c}\text { Number of } \\
\text { iteration } \mathbf{i}\end{array}$ & $|\mathbf{F}(\mathbf{z})|$ & $\begin{array}{c}\text { Number of } \\
\text { iteration } \mathbf{i}\end{array}$ & $|\mathbf{F}(\mathbf{z})|$ \\
\hline 1 & 0.61619 & 14 & 0.35866 \\
\hline 2 & 0.5189 & 15 & 0.35835 \\
\hline 3 & 0.288 & 16 & 0.35852 \\
\hline 4 & 0.43079 & 17 & 0.35842 \\
\hline 5 & 0.32218 & 18 & 0.35848 \\
\hline 6 & 0.37886 & 19 & 0.35845 \\
\hline 7 & 0.34703 & 20 & 0.35846 \\
\hline 8 & 0.36492 & 21 & 0.35845 \\
\hline 9 & 0.35484 & 22 & 0.35846 \\
\hline 10 & 0.36049 & 23 & 0.35846 \\
\hline 11 & 0.35732 & 24 & 0.35846 \\
\hline 12 & 0.3591 & 25 & 0.35846 \\
\hline 13 & 0.3581 & 26 & 0.35846 \\
\hline
\end{tabular}

Fig.20: Observation : the value converges to a fixed point after 22 iterations

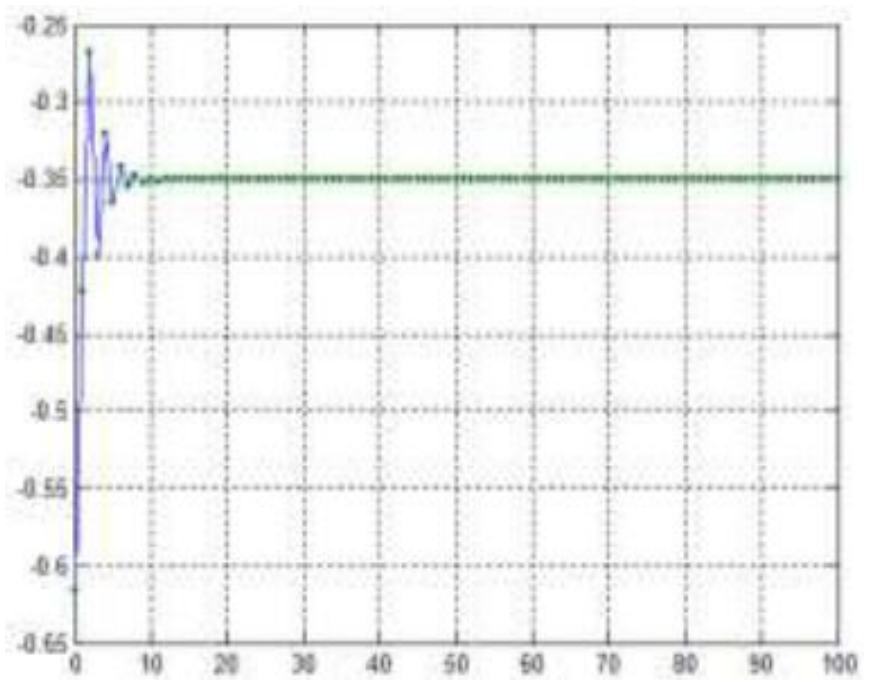

Fixed points for cubic polynomial [2]:

Table 5: Orbit of $\mathrm{F}(\mathrm{z})$ at $\mathrm{s}=0.4$ and $\mathrm{s}^{\prime}=0.2$

for $(\mathrm{z} 0=-0.0189704705+0.02867852789 \mathrm{i})$

\begin{tabular}{|c|c|c|c|}
\hline $\begin{array}{c}\text { Number of } \\
\text { iteration } \mathbf{i}\end{array}$ & $|\mathbf{F}(\mathbf{z})|$ & $\begin{array}{c}\text { Number of } \\
\text { iteration } \mathbf{i}\end{array}$ & $|\mathbf{F}(\mathbf{z})|$ \\
\hline 18 & 0.6098 & 28 & 0.50274 \\
\hline 19 & 0.45643 & 29 & 0.50223 \\
\hline 20 & 0.52977 & 30 & 0.50252 \\
\hline
\end{tabular}

\begin{tabular}{|c|c|c|c|}
\hline 21 & 0.4871 & 31 & 0.50236 \\
\hline 22 & 0.51134 & 32 & 0.50245 \\
\hline 23 & 0.49733 & 33 & 0.5024 \\
\hline 24 & 0.50536 & 34 & 0.50243 \\
\hline 25 & 0.50073 & 35 & 0.50241 \\
\hline 26 & 0.50339 & 36 & 0.50242 \\
\hline 27 & 0.50186 & 37 & 0.50242 \\
\hline
\end{tabular}

Fig.21: Observation : we skipped 17 iteration and the value converges to a fixed point after 36 iterations

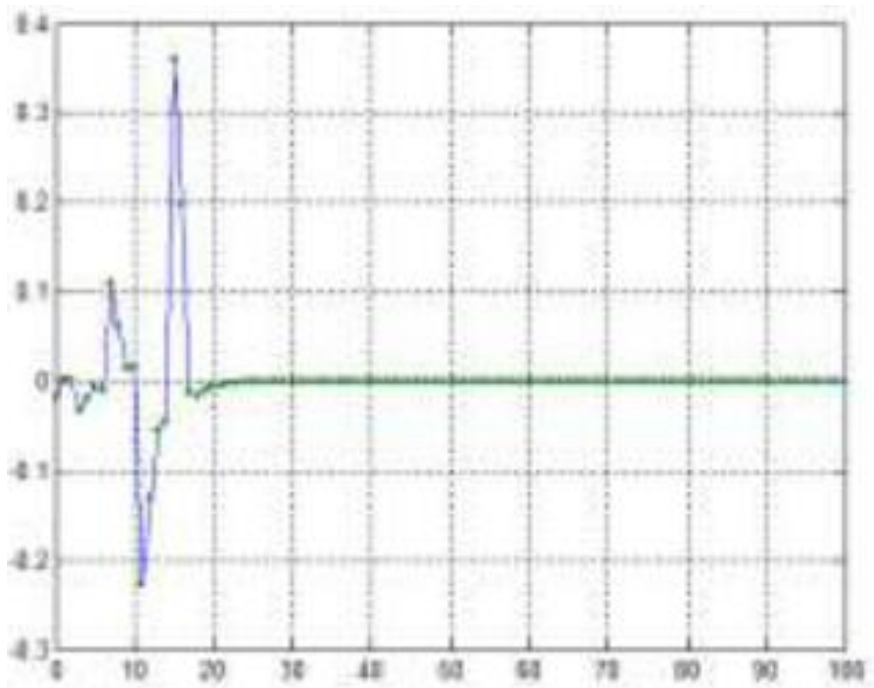

Generation of Relative Superior Mandel-bar Set:

Fig.22: For quadratic function: $\mathrm{s}=0.6, \mathrm{~s}^{\prime}=0.2$

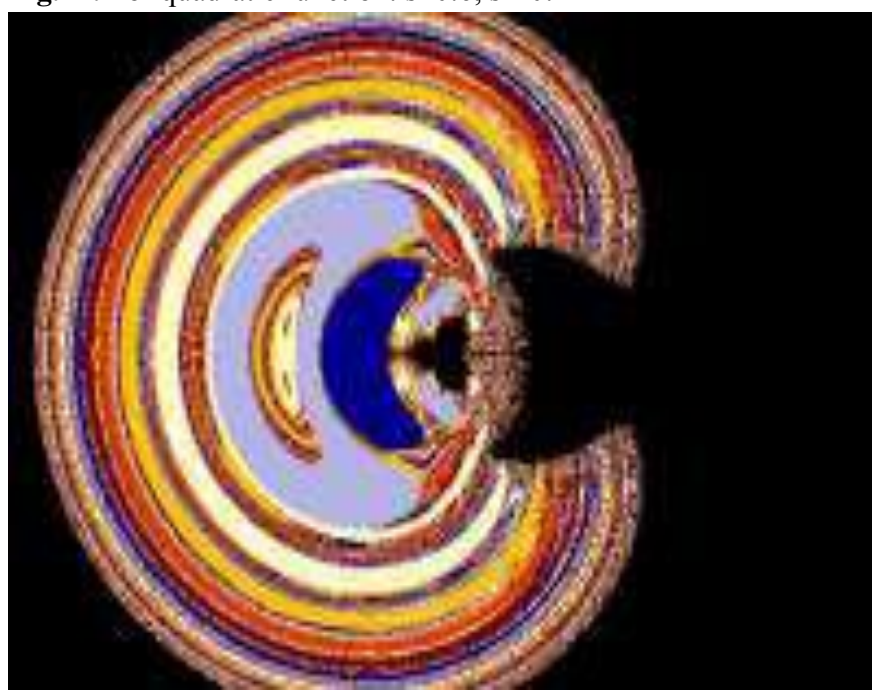


Fig.23: For cubic function: $\mathrm{s}=0.4, \mathrm{~s}=0.2$

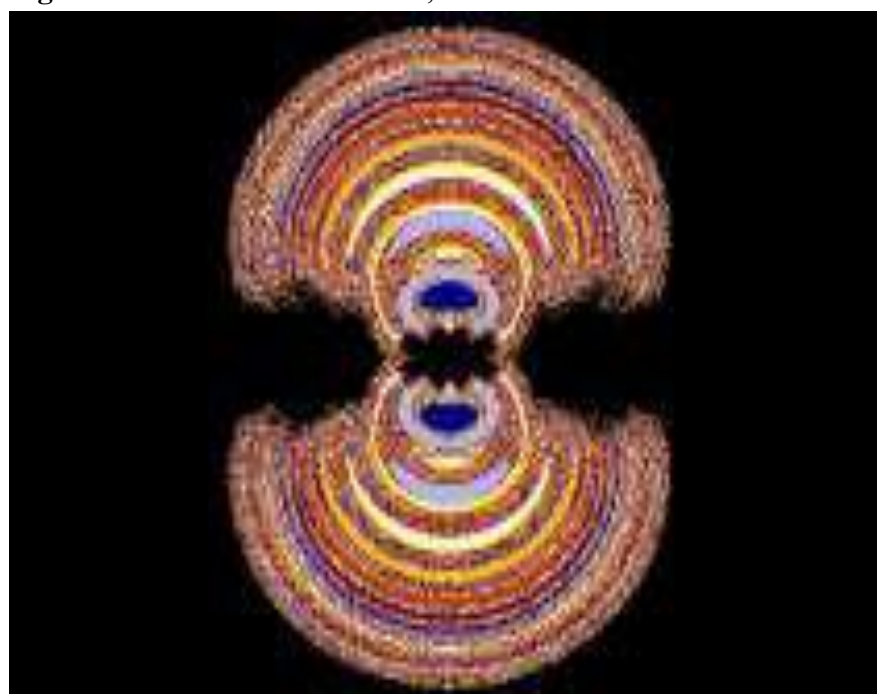

Fig.24: For bi-quadratic function: $\mathrm{s}=0.6, \mathrm{~s}^{\prime}=0.2$

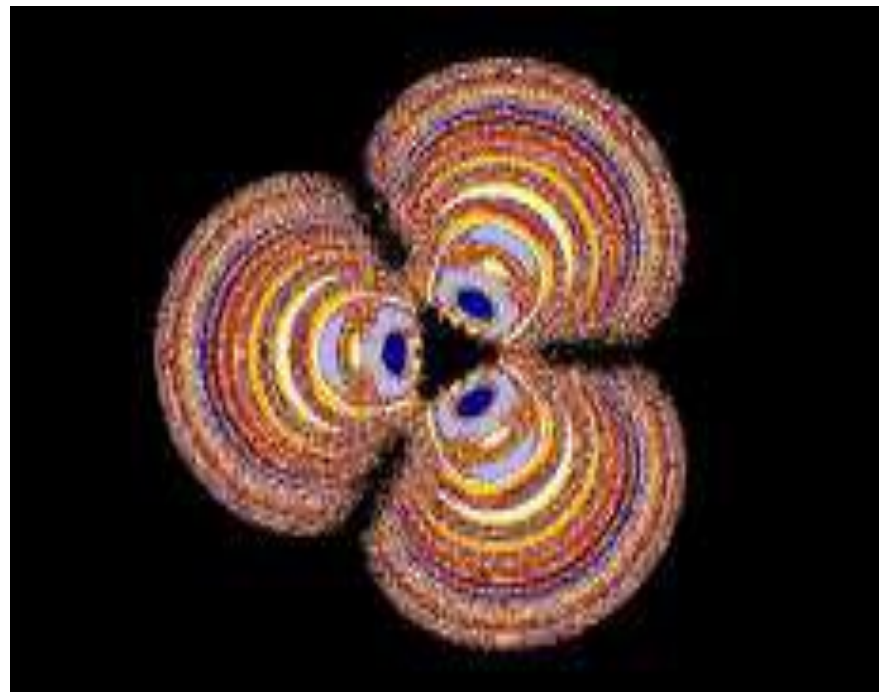

Fig.25: Generalization of RSMB : $\mathrm{s}=0.5, \mathrm{~s}^{\prime}=0.2, \mathrm{n}=19$

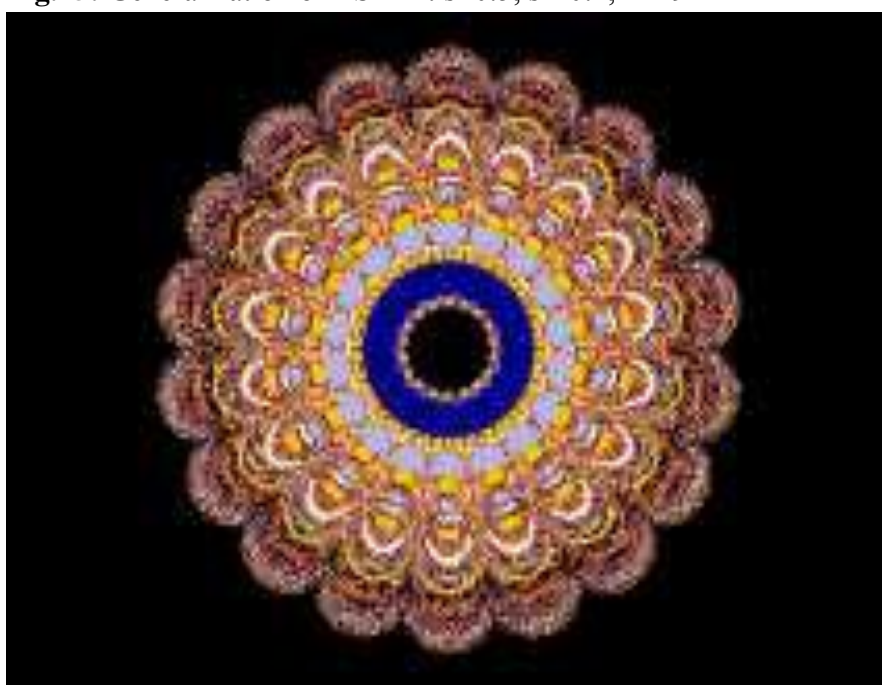

Generation of Relative Superior Julia Sets for Mandel-bar set:
Fig.26: For quadratic function: $\mathrm{s}=0.6, \mathrm{~s}{ }^{\prime}=0.2$,

$\mathrm{c}=0.08166620257+0.00739899807 \mathrm{i}$

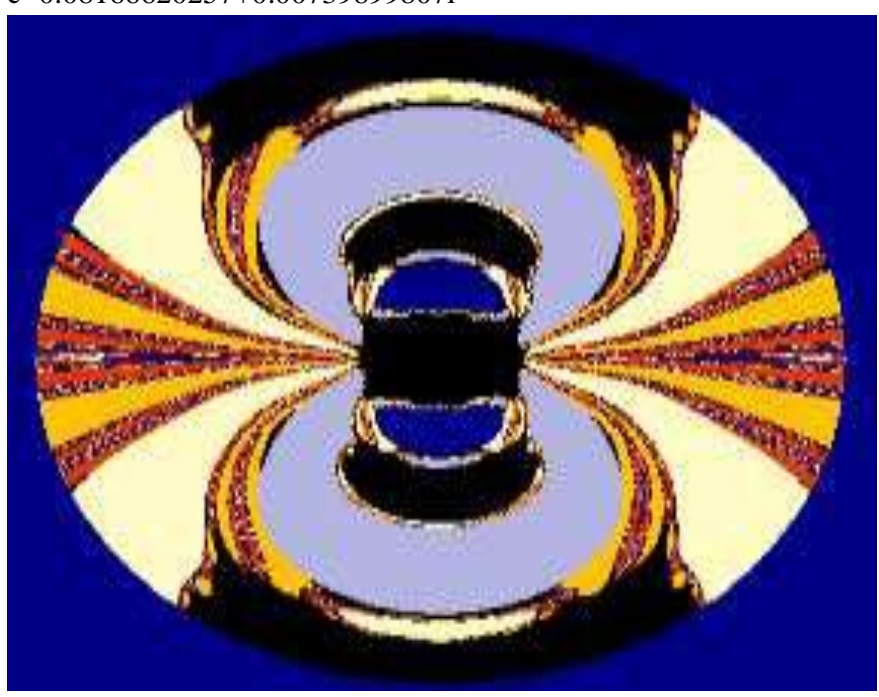

Fig.27: For cubic function: $\mathrm{s}=0.8, \mathrm{~s}=0.3, \mathrm{c}=-$

$0.003854849909+0.01666833389$

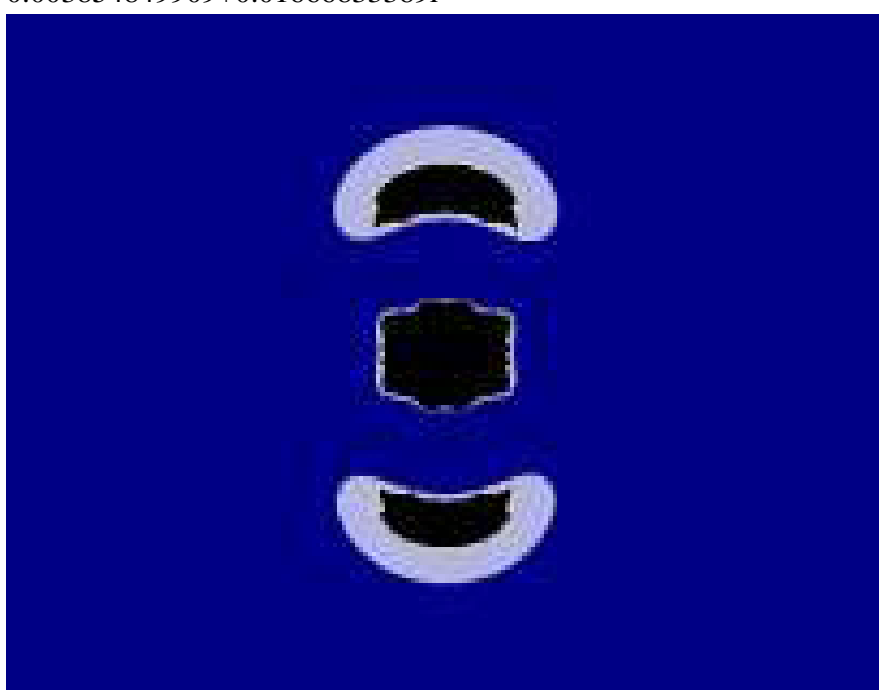

\section{CONCLUSION}

- The $\mathrm{z}$ plane fractal image for the function $z \rightarrow z^{2}+c, n \geq 2$ showed that the stable region is bounded by unstable region. Besides this, the non integer value change brought the embryonic structure in the form of lobe.

- On the other hand the c plane geometrical analysis of the function $z \rightarrow\left(z^{n}+c\right)^{-1}, n \geq 2$ represented the planetary type structure comprising of central planet with satellites. Here non integer value change showed the embryonic self similar growth in satellite pattern.

- Relative Superior Mandelbrot of inverse function showed lace like structure with multi-coloured small circles. Geometrical analysis of Relative Superior Julia sets of inverse function shows that the boundary of fixed point region forms a $(n+1)$ hypocycloid. 
- The geometry of Relative Superior Mandelbrot set and Relative Superior Julia sets of inverse function showed their rotational as well as reflection symmetry. One of the most fascinating results is the central planet with satellite like structure obtained for biquadratic Relative Superior Julia sets.

- Further, for the odd value of $\mathrm{n}$, all the Relative Superior Mandelbar sets are symmetrical objects, and for the even values of $n$, all the relative superior Mandelbar sets are symmetrical about $\mathrm{x}$-axis. Besides this, our antifractals are different from the normal Tricorns and Multicorns as they have (n-1) wings.

\section{ACKNOWLEDGMENTS}

Our thanks to Dr. A.K. Swami, Principal, G.B.Pant Engineering College, Ghurdauri, for providing necessary infrastructure for the research work. We would also like to thank Mrs. Priti Dimri, Head, Department of Computer Science and Engineering, G.B.Pant Engineering College, Ghurdauri, for her unconditional and valuable support in writing this paper.

\section{REFERENCES}

[1] Yashwant S Chauhan, Rajeshri Rana, and Ashish Negi, "Complex Dynamics of Ishikawa Iterates for Non Integer Values", International Journal of Computer Applications (0975-8887) Volume 9- No.2,October 2010

[2] Yashwant S. Chauhan, Rajeshri Rana, Ashish Negi, "Mandel-Bar Sets of Inverse Complex Function", International Journal of Computer Applications (09758887) Volume 9- No.2, November 2010

[3] W.D.Crowe, R.Hasson, P.J.Rippon, and P.E.D. StrainClark, "On the structure of the Mandel-bar set", Nonlinearity(2)(4)(1989), 541-553. MR1020441

[4] Robert L. Devaney, "A First Course in Chaotic Dynamical System: Theory and Experiment", AddisonWesley, 1992. MR1202237

[5] S.Dhurandar, V.C.Bhavsar and U.G.Gujar, "Analysis of z-plane fractal images from $z \leftarrow z^{\alpha}+c$ for $\alpha<0$ " Computers and Graphics 17,1(1993), 89-94
[6] U.G. Gujar and V.C. Bhavsar, "Fractals from $z \leftarrow z^{\alpha}+c$ in complex c-Plane", Computers and Graphics 15, 3 (1991), 441-449

[7] U.G. Gujar, V.C. Bhavsar and N. Vangala, "Fractals from $z \leftarrow z^{\alpha}+c$ in complex z-Plane", Computers and Graphics 15, 4 (1991), 45-49

[8] S. Ishikawa, "Fixed Points by a new iteration method", Proc. Amer. Math. Soc.44 (1974), 147-150

[9] G. Julia, "Sur 1' iteration des functions rationnelles", J Math Pure Appli. 8 (1918), 737-747

[10] Eike Lau and Dierk Schleicher, "Symmetries of fractals revisited.", Math. Intelligencer (18)(1)(1996), 45-51.

[11] B. B. Mandelbrot, "The Fractal Geometry of Nature", W. H. Freeman, New York, 1983.

[12] J. Milnor, "Dynamics in one complex variable; Introductory lectures", Vieweg (1999).

[13] Rajeshri Rana, Yashwant S. Chauhan, Ashish Negi, "Inverse Complex Function Dynamics of Ishikawa Iterates", International Journal of Computer Applications (0975-8887) Volume 9- No.1, November 2010

[14] K.W. Shirriff, "An investigation of fractals generated by $z \rightarrow z^{-n}+c$ ", Computers and Graphics 13, 4 (1993), 603-607

[15] N.Shizuo and Dierk Schleicher, "Non-local connectivity of the Tricorn and Multicorns", Dynamical system and chaos (1) (Hachioji, 1994), 200-203, World Sci. Publ., River Edge, NJ, 1995 MR1479931

[16] N. Shizuo and Dierk Schleicher, "On multicorns and unicorns: I. Antiholomorphic dynamics. Hyperbolic components and real cubic polynomials", Internat. J. Bifur. Chaos Appl. Sci. Engrg, (13)(10)(2003), 28252844.

[17] R. Winters, "Bifurcations in families of Antiholomorphic and biquadratic maps", Thesis, Boston Univ. (1990). 